\title{
Diskussion zeichnet düstere Aussichten für die Werte der EU
}

Es war ein Thema, das angesichts der aktuellen Flüchtlingskrise und der fast schon in Vergessenheit geratenen Eurokrise zahlreiche Teilnehmer zum diesjährigen Forum Freiheit der HayekStiftung in Berlin zog: Zerfällt die Europäische Union? - So lau-

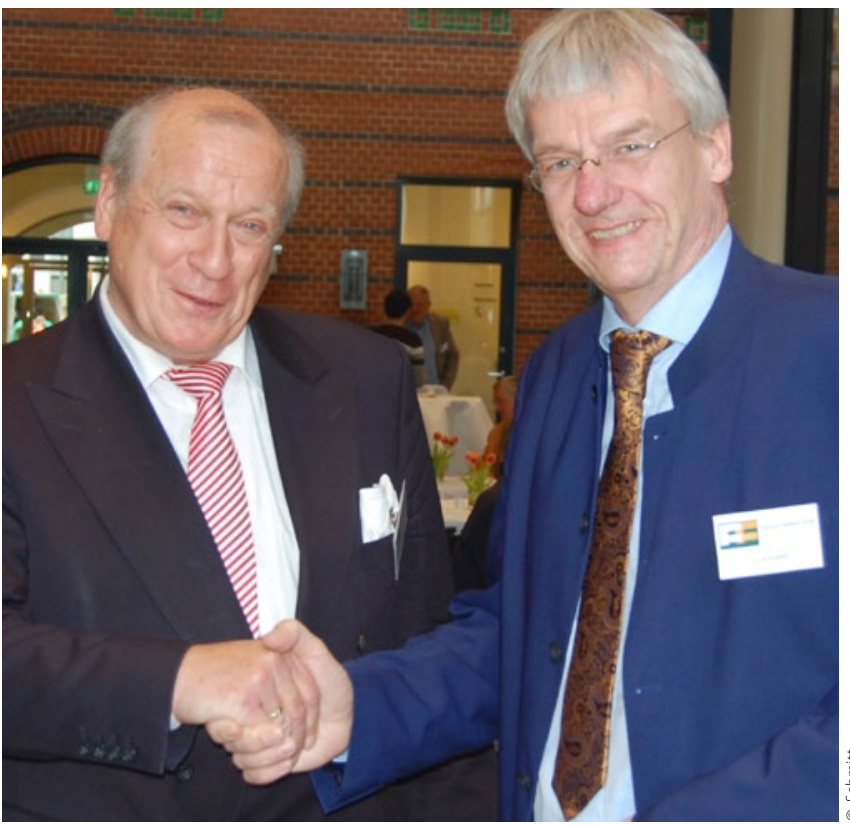

tete die Leitfrage, der sich die Gesellschaftswissenschaftler, Ökonomen, Juristen und Politiker in drei großen Diskussionsrunden widmeten. Streng um die Finanzen sowie die Möglichkeiten und Grenzen von Solidarität ging es im ersten Panel, das sich mit der Europäischen Währungsunion und der Zukunft des Euro beschäftigte.

Im Sperrfeuer der Kritik stand die Geldpolitik der Europäischen Zentralbank und der deutschen Bundesregierung. (Fast) einhellige Meinung auf dem Podium: Die Überlebenschancen des Euro stehen schlecht. In den beiden anderen Diskussionsrunden ging es um den Erhalt der Freizügigkeit und des gemeinsamen Binnenmarkts in der EU, die als große Errungenschaften gewürdigt wurden. Angesichts des aktuellen Flüchtlingszustroms seien die freiheitlichen Werte der EU und ihre Mitgliedstaaten jedoch in Frage gestellt, monierten die Podiumsteilnehmer.

„Zwischen Überzentralisierung und Desintegration“ lautete der Untertitel des Forum Freiheit in diesem Jahr. Womit auch das Ergebnis der hochkarätig besetzten Freidenker-Runde bereits vorweggenommen war. Für den Freien Verband Deutscher Zahnärzte (FVDZ) nahmen der Bundesvorsitzende Harald Schrader (hier im Bild mit Prof. Dr. Gerd Habermann, dem Initiator und Mitbegründer der Friedrich A. von Hayek-Gesellschaft und Vorstandsvorsitzender der Hayek-Stiftung für eine freie Gesellschaft) sowie weitere Vertreter des Bundesvorstandes an der Diskussionsveranstaltung teil.

\section{Hilfe für Flüchtlinge an der mazedonischen Grenze}

In Deutschland kommen nach der Schließung der mazedonischen Grenze und damit der von vielen Flüchtlingen genutzten Balkanroute immer weniger Flüchtlinge an. Für viele Menschen, die aus ihren Heimatländern geflohen sind, endet die Flucht seit einigen Wochen in dem griechischen Grenzort Idomeni. Etwa 12.000 bis 14.000 Flüchtlinge, darunter viele Kinder, sind nach Angaben der Stiftung Hilfswerk Deutscher Zahnärzte für Lepra- und Notgebiete (HDZ) nach der Grenzschließung Mazedoniens in einem Auffanglager dort gestrandet. „Sie müssen dort ohne ausreichende medizinische Versorgung auskommen“, erläuterte HDZ-Vorsteher Dr. Klaus Winter. Daher habe das HDZ beschlossen, das Deutsche Rote Kreuz (DRK) in seinen verstärkten Nothilfeaktivitäten in Idomeni zu unterstützen. „Die Menschen vor Ort brauchen dringend Medikamente und lebensnotwendige Hilfsgüter“, betonte auch Dr. Peter Engel, Präsident der Bundeszahnärztekammer (BZÄK). Die Bundeszahnärztekammer ist Schirmherrin der Stiftung Hilfswerk Deutscher Zahnärzte, der größten zahnärztlichen Hilfsorganisation. BZÄK und HDZ bitten um Spenden, um in Zusammenarbeit mit dem DRK im griechischen Grenzgebiet vor Ort zielgerichtet helfen zu können. Gespendet werden kann unter folgender Bankverbindung:

\section{Hilfswerk Deutscher Zahnärzte}

Deutsche Apotheker- und Ärztebank IBAN: DE28 300606010004444000 BIC: DAAEDEDD

Stichwort: Idomeni

Eine Spendenbescheinigung wird bei genauer Adressenangabe ausgestellt. Zur Steuerbegünstigung bis 200 Euro kann als vereinfachter Zuwendungsnachweis nach $₫ 50$ Abs. 2 EStDV der Kontoauszug vorgelegt werden.

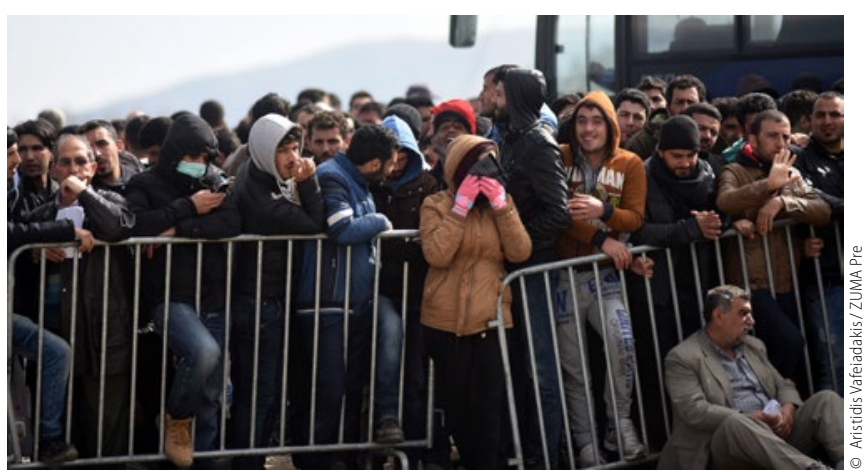

